\title{
Perspectives in Microvascular Fluid Handling: Does the Distribution of Coagulation Factors in Human Myocardium Comply with Plasma Extravasation in Venular Coronary Segments?
}

\author{
Matthias Jacob ${ }^{a, b} \quad$ Daniel Chappell ${ }^{a, b} \quad$ Mechthild Stoeckelhuber ${ }^{c}$ \\ Ulrich Welsch $^{c}$ Markus Rehm ${ }^{a}$ Dirk Bruegger ${ }^{a}$ Ingo Kaczmarek ${ }^{d}$ \\ Peter Conzen $^{\text {a }}$ Bernhard F. Becker ${ }^{b}$ \\ ${ }^{a}$ Clinic of Anesthesiology, ${ }^{b}$ Walter-Brendel Centre of Experimental Medicine, ' Institute of Anatomy, and \\ ${ }^{\mathrm{d} C l i n i c}$ of Cardiac Surgery, Ludwig-Maximilians-University, Munich, Germany
}

\section{Key Words}

Coagulation factors $\cdot$ Protein C $\cdot$ Thrombomodulin $\cdot$ Tissue factor $\cdot$ Venules

\begin{abstract}
Background: Heterogeneity of vascular permeability has been suggested for the coronary system. Whereas arteriolar and capillary segments are tight, plasma proteins pass readily into the interstitial space at venular sites. Fittingly, lymphatic fluid is able to coagulate. However, heart tissue contains high concentrations of tissue factor, presumably enabling bleeding to be stopped immediately in this vital organ. The distribution of pro- and anti-coagulatively active factors in human heart tissue has now been determined in relation to the types of microvessels. Methods and Results: Samples of healthy explanted hearts and dilated cardiomyopathic hearts were immunohistochemically stained. Albumin was found throughout the interstitial space. Tissue factor was packed tightly around arterioles and capillaries, whereas the tissue surrounding venules and small veins was
\end{abstract}

practically free of this starter of coagulation. Thrombomodulin was present at the luminal surface of all vessel segments and especially at venular endothelial cell junctions. Its product, the anticoagulant protein $C$, appeared only at discrete extravascular sites, mainly next to capillaries. These distribution patterns were basically identical in the healthy and diseased hearts, suggesting a general principle. Conclusions: Venular extravasation of plasma proteins probably would not bring prothrombin into intimate contact with tissue factor, avoiding interstitial coagulation in the absence of injury. Generation of activated protein C via thrombomodulin is favored in the vicinity of venular gaps, should thrombin occur inside coronary vessels. This regionalization of distribution supports the proposed physiological heterogeneity of the vascular barrier and complies with the passage of plasma proteins into the lymphatic system of the heart.

Copyright $\odot 2010$ S. Karger AG, Basel

M. Jacob and D. Chappell contributed equally to this work.

\section{KARGER}

Fax +41613061234 E-Mail karger@karger.ch www.karger.com
(C) 2010 S. Karger AG, Basel

$1018-1172 / 11 / 0483-0219 \$ 38.00 / 0$

Accessible online at:

www.karger.com/jvr
Dr. med. Matthias Jacob

Clinic of Anesthesiology, Ludwig-Maximilians-University

Nussbaumstrasse 20, DE-80336 Munich (Germany)

Tel. +49 895160 2691, Fax +49 8951604446

E-Mail matthias.jacob@med.uni-muenchen.de 


\section{Introduction}

As early as 1653 , the physiologist Olaus Rudbeck had realized that the lymphatic fluid is capable of coagulation $[1,2]$. This ability makes it mandatory for plasma coagulation factors to extravasate somewhere in the vascular bed, a fact later ignored by Ernest Starling when formulating his classical concept of fluid homeostasis in the vasculature [3]. In many tissues, interstitial and lymphatic protein levels have been found to be far higher than previously assumed and, surprisingly, to have next to no impact on fluid exchange across the capillary wall, provided the endothelium is endowed with an intact glycocalyx [4]. In fact, the oncotic gradient established by plasma proteins across the glycocalyx from lumen to endothelial membrane surface determines the effective filtration pressure [5]. In addition to this glycocalyx effect there are only very narrow strand gaps between adjoining endothelial cells [4]. Thus, outward fluid filtration and protein passage in the arteriolar and capillary segments must be expected to be very low. Furthermore, contrary to Starling's postulate, no net resorption occurs in the venular sections of the vasculature of most organs [6].

We have recently described, based on studies in isolated heart preparations, that the coronary bed exhibits a non-uniform filtration behavior, namely extremely low filtration and little egress of colloid in the arteriolar and capillary beds, as opposed to ready access of intravascular colloids to the interstitial space in the venular sections [7]. However, with both hydrostatic and oncotic pressure gradients being small in the latter segments, there is little driving force for fluid movement [7]. The net result is a low-filtration state 'paradoxically' associated with high interstitial plasma colloid levels.

The physiological problem with such a condition is evident: should extravasating zymogens of plasma coagulation factors meet up with their activators, then the interstitial space would be plugged by fibrin. Indeed, the myocardium has been reported to express high levels of tissue factor, one of the most potent stimuli for rapid coagulation $[8,9]$ and one that is normally not in direct contact with the bloodstream [10]. However, the fibrinogencleaving power of thrombin can be effectively countered in plasma by inhibitory systems, foremost activated protein C (APC). This is produced from the zymogen protein $\mathrm{C}$ by the endothelial membrane protein thrombomodulin, acting in conjunction with thrombin $[11,12]$, and could also be passed on into tissue via the venular gaps.

The explanation why coagulation obviously does not normally occur in the interstitial space of the heart, de- spite the proposed facile extravasation of plasma protein constituents, remains elusive. By staining human myocardium for albumin, tissue factor, thrombomodulin and its anticoagulatory product APC, we sought to obtain histological insight into the seeming physiological paradox: coagulability of lymphatic fluid on the one hand, and pro-coagulatory tissue activity on the other.

\section{Materials and Methods}

Human heart tissue was obtained (with consent from the nearest relatives) from two explanted healthy hearts that had, unfortunately, not become available to the prospective recipients in time because of logistical reasons ('healthy'), and (with prior informed consent) from three 'diseased' organs. Two were adults with explantation necessitated by dilated cardiomyopathy (DCM), the third was a 1-year-old subject with DCM. In the latter case we examined surgical material obtained at implantation of a left ventricular assist device. For the adult hearts, macroscopically healthy sections of the left ventricle, 4 from each individual heart, were finely diced with a scalpel (approx. 1-2-mm cubes) and immersed in formaldehyde solution (4.5\%), fixed (formalin 4.5\%), dehydrated and embedded in paraffin. Tissue slices were deparaffinated and, to demask the tissue antigens, subjected to microwave treatment in citrate buffer at $\mathrm{pH} 6.0(3 \times 5 \mathrm{~min})$. After blocking endogenous peroxidase activity ( $3 \%$ hydrogen peroxide, $15 \mathrm{~min}$ ), the sections were treated with $3 \%$ normal goat serum (Vector Laboratories, Burlingame, Calif., USA) or 3\% porcine serum (albumin staining) for $30 \mathrm{~min}$.

\section{Staining for Human Albumin}

Tissue slices were stained using a monoclonal mouse antibody against human albumin (Clone HSA-11; Sigma, St. Louis, Mo., USA) and then with a secondary antibody (Anti-mouse IgG, goat, biotinylated; Vector Laboratories; diluted 1:50), together with a reaction kit (Vectastain, Vector Laboratories). Histogreen (Linaris, Wertheim, Germany) served as chromogen.

Staining for Tissue Factor and Evaluation of Distribution

A primary monoclonal mouse antibody against the CD 142 epitope of tissue factor (Acris Antibodies, Hiddenhausen, Germany) diluted 1:100 was applied for $2 \mathrm{~h}$ at room temperature; the secondary antibody was diluted 1:200. Diaminobenzidine (DAB) was used as chromogen together with the Vectastain kit. Tissue was counterstained with hematoxylin.

Three blinded experts (M.R., D.B., P.C.) were independently provided with 2-5 different slices of healthy or diseased heart preparations and asked to first identify vessels belonging to three different categories: artery/arteriole, capillary and venule/vein. For each identified vessel they were then required to rate the intensity of staining found within a $20-\mu \mathrm{m}$ border zone of the vessel lumen using a decimal scale ranging from 0 (no stain) to 10 (intense stain completely surrounding the vessel). The data are presented as median, smallest observation, lower and upper 95th and 97th percentile and largest observation, with $n$ indicating the total number of vessels analyzed per category. For comparisons of multiple groups, analysis of variance (ANOVA) was performed. Post 
hoc tests were performed using the Bonferroni method. $\mathrm{p}<0.05$ was considered to be significant. The statistical software used to conduct the analyses was SPSS 16 (SPSS Inc., Chicago, Ill., USA).

\section{Staining for Thrombomodulin and Protein C}

Detection was performed according to the avidin-biotinhorseradish-peroxidase-complex method using the Vectastain kit. The monoclonal antibodies to thrombomodulin (Dako, Hamburg, Germany) and protein C (Upstate, Lake Placid, N.Y., USA) were diluted 1:100 and applied for $1 \mathrm{~h}$ at room temperature and overnight at $4^{\circ} \mathrm{C}$. The second, biotinylated antibody (anti-mouse; Vector Laboratories) was diluted 1:50 and applied for $45 \mathrm{~min}$ at room temperature. After rinsing with PBS, incubation with peroxidase-labeled streptavidin (45 min, room temperature), and renewed rinsing, peroxidase activity was visualized with $\mathrm{DAB}$ and $\mathrm{H}_{2} \mathrm{O}_{2}$. Tissue was counterstained with hematoxylin.

Light microscopy was performed using a Nikon eclipse $80 \mathrm{i}$ microscope (Nikon, Düsseldorf, Germany; $20 \times$ objective lens, Nikon Plan apo, N.A. 0.75 and $40 \times$ objective lens, Nikon Plan, N.A. 0.65) The imaging medium was air, no fluorochromes were used and images were captured with a Nikon digital camera DS$5 \mathrm{M}$ and processing in Adobe Photoshop 7.0.

\section{Results}

The healthy human hearts revealed the presence of albumin not only at the coronary vessel walls, but also throughout the interstitial space, especially the outside of the muscle cells, which were highly positive (see green color in fig. 1a, b). Intense staining for albumin was also found throughout the interstitial space of hearts with dilated cardiomyopathy (fig. 1c). Tissue factor was evidenced as brown, granular staining in and on various cells of the heart tissue, both in healthy and diseased samples. We found a high concentration of tissue factor around the arterioles and the capillaries, but almost none around the venules and small veins (see fig. 1d-f). Thrombomodulin, an endothelial inhibitor of coagulation, was found as expected at the luminal surface of all vessels (fig. 1g-i). Staining was extremely intense at endothelial cell junctions in large venules (black arrowhead in fig. $1 \mathrm{~h}$ ). APC was identified around small vessels (fig. $1 j-1$ ). The localization appeared to coincide approximately with that of tissue factor, as noted before. No protein C staining occurred at the luminal surface of coronary vessels in the heart specimens examined here (cf. fig. $1 \mathrm{j}-\mathrm{l}$ ).

Comparable distributions of tissue factor and thrombomodulin were found in the tissue slices obtained from a further healthy heart and another 2 hearts that had developed dilated cardiomyopathy (fig. 2). With respect to tissue factor, this again proved to be localized around capillaries (fig. 2a) and to be absent from around venules (fig. 2b). An intense luminal expression of thrombomodulin (brown coloration) is demonstrated in figure $2 \mathrm{c}$ for an arteriole of $50 \mu \mathrm{m}$ diameter in a slice from a healthy heart. An example of dense localization of thrombomodulin to a small venule is shown in figure $2 \mathrm{~d}$.

Although specific tissue localizations of the 3 factors investigated here with respect to the various categories of microvessel were the same for healthy and diseased hearts, samples obtained from the latter did show by far denser connective tissue. This feature is most apparent in figure $1 \mathrm{c}, \mathrm{i}$ and in figure $2 \mathrm{a}, \mathrm{d}$ when these are compared to the accompanying pictures of healthy tissue.

Quantitative evaluation of the vessel-specific distribution of tissue factor, performed by expert rating, is shown in a box plot in figure 3. Both in the healthy hearts (fig. 3a) and in the diseased hearts (fig. 3b) there was tissue factor around arterioles, small arteries and capillaries, with significantly less (practically none) around venules and small veins.

\section{Discussion}

An important first result of the present work concerns the fact that the plasma protein albumin was present in substantial amounts within the interstitial space of all the myocardial tissue samples examined, irrespective of whether they had been derived from healthy or diseased organs. This supports the concept of ready extravasation of plasma proteins from the microvasculature under physiological conditions $[1,4]$, extended to the heart in recent studies [7].

The modern, glycocalyx-dependent concept of cardiac vascular/interstitial fluid handling [4, 7], reconciling low fluid filtration with egress of plasma proteins, is outlined schematically in figure 4, along with supportive immunohistochemical and electron microscopical findings obtained on isolated perfused heart preparations. In the arteriolar and capillary segments (fig. 4a), the intact endothelial glycocalyx retains plasma proteins, creating an oncotic gradient between lumen and endothelial surface (but not necessarily between lumen and interstitial space, see below). In conjunction with narrow endothelial clefts this opposes the hydrostatically driven outflow of plasma. The net result is one of low flow, with little transport of plasma constituents (fig. 4a, top) [4, 7]. This is evidenced by the absence of human albumin (green stain) in the pericapillary space after brief ( $2 \mathrm{~min}$ ) intracoronary application to isolated guinea pig hearts (fig. 4a, middle) [7]. Also, the stain containing lanthanum and glutaraldehyde, applied 

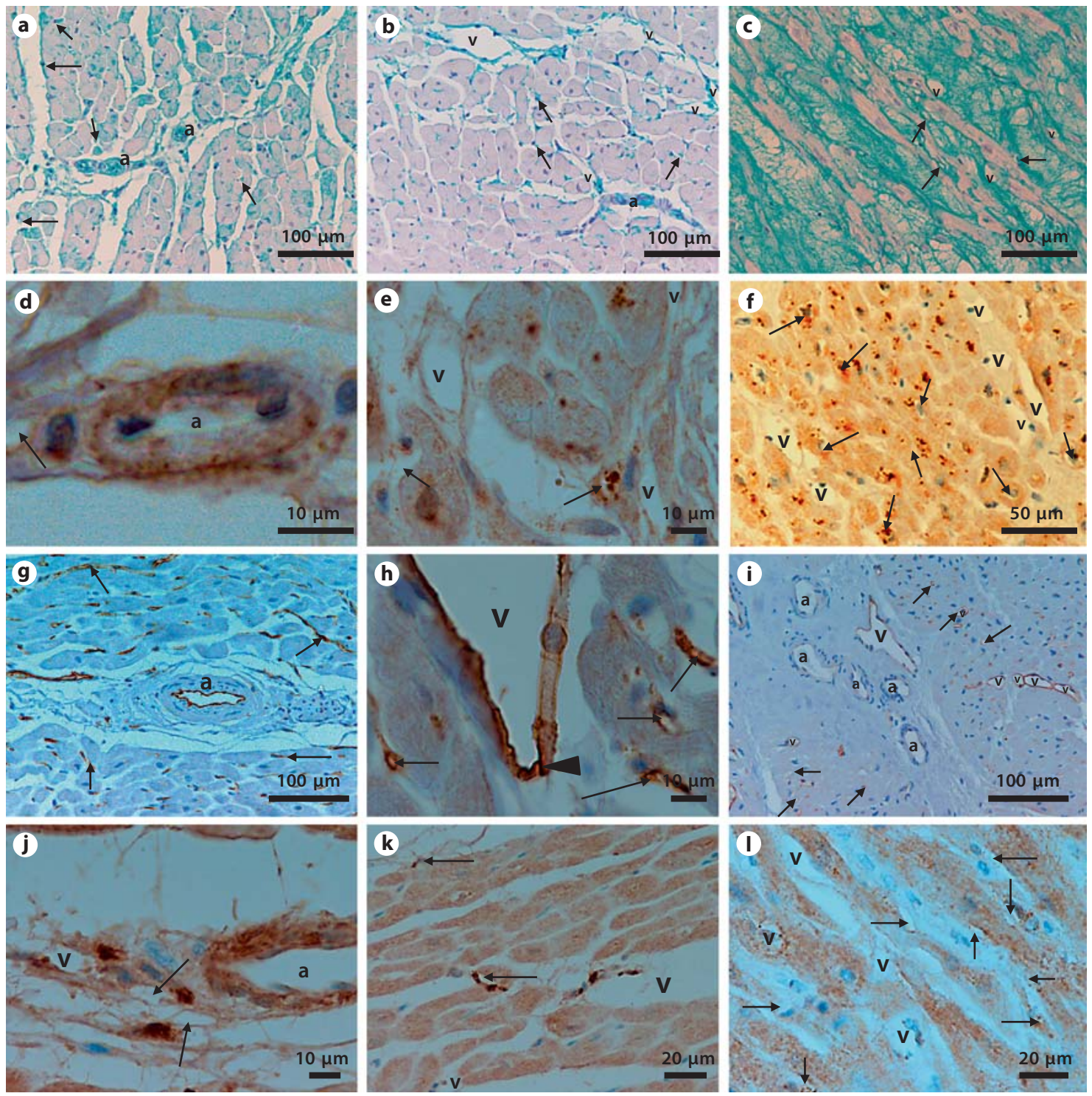

Fig. 1. Examples of distribution of albumin (a-c, green stain), tissue factor (d-f, brown stain), thrombomodulin ( $\mathbf{g}-\mathbf{i}$, brown stain) and protein C (j-l, brown stain) in ventricular tissue, comparing a healthy human heart (left and middle columns) and a heart from an adult suffering from dilated cardiomyopathy (right column). The left column highlights arteriolar and capillary vessels, the middle and right columns preferentially venular and

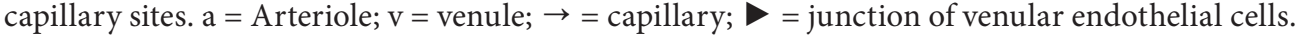

to preserve the endothelial glycocalyx for electron microscopy [13], does not spread beyond the luminal caveolae in capillaries (fig. 4a, bottom) [7]. In the venular segments (fig. 4b), large pores between the endothelial cells allow free and easy access of plasma constituents to the interstitial space. However, bulk plasma outflow towards this compartment and movement of fluid plus solutes in the opposite direction are low, because both the hydrostatic and the oncotic pressure differences are small (fig. $4 \mathrm{~b}$, top).
Accordingly, in isolated guinea pig hearts, the intravascularly applied markers albumin (fig. 4b, middle) and glycocalyx-fixative (fig. 4b, bottom) appear within minutes also in the interstitial space next to venules and small veins and on abluminal cell surfaces, respectively [7].

Since albumin passes readily into the interstitial space, the same should hold true for plasma coagulation factors. Accordingly, we postulated that the distribution of tissue factor in heart tissue cannot be homogeneous, but per- 
Fig. 2. Examples of the distribution of tissue factor ( $\mathbf{a}, \mathbf{b}$, brown stain) and thrombomodulin (c, d, brown stain) in ventricular tissue of human hearts. a, b, d Samples from subjects suffering from dilated cardiomyopathy. a One-year-old subject. b, d Adult. b Positive staining of intravascular monocytes as opposed to no stain around the venule. $\mathbf{c}$ Thrombomodulin in an arteriole of $50 \mu \mathrm{m}$ diameter of a healthy heart. $\mathrm{a}=$ Arteriole; $\mathrm{v}=$ venule; $\rightarrow$ = capillary.
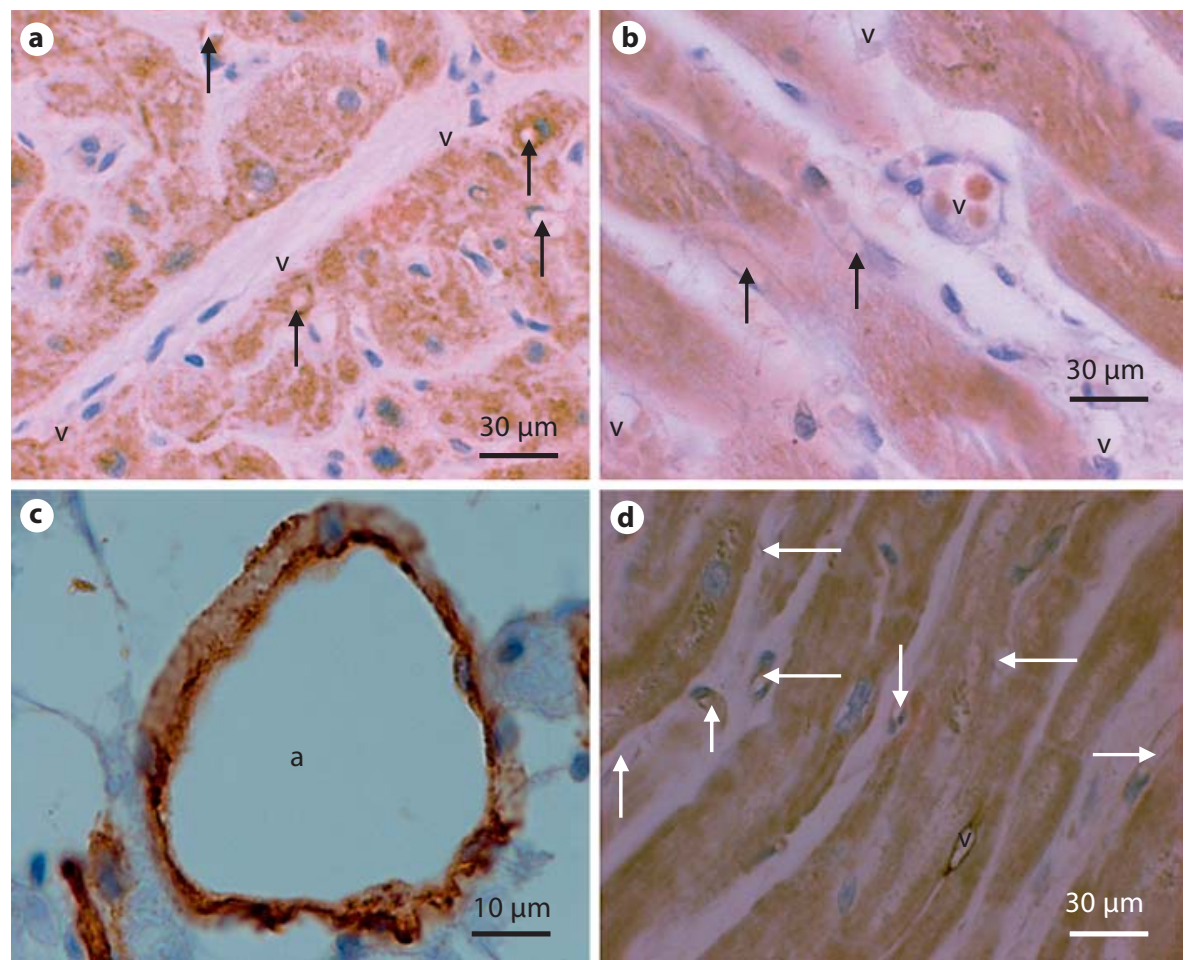
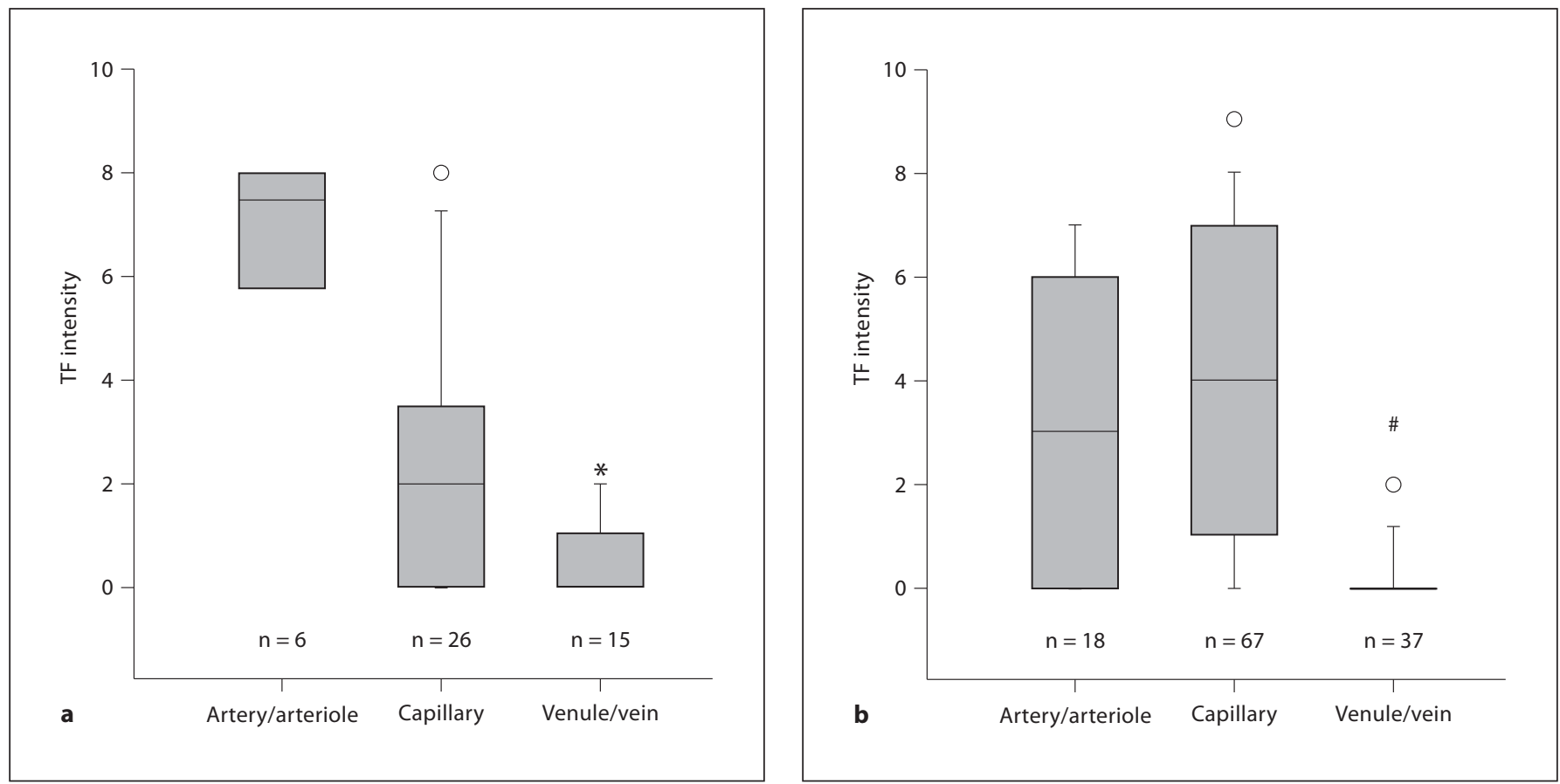

Fig. 3. Blinded expert-rated results of tissue factor immunostaining for different categories of vessels. Results were rated within a $20-\mu \mathrm{m}$ border zone outside of the vessel using a decimal scale ranging from 0 (no stain) to 10 (intense stain completely surrounding the vessel). ${ }^{*} \mathrm{p}<0.05$ vs. artery/arteriole. ${ }^{\#} \mathrm{p}<0.05$ vs. other vessel categories; a healthy hearts, $\mathbf{b}$ diseased hearts. 
Arteriolar/capillary segments

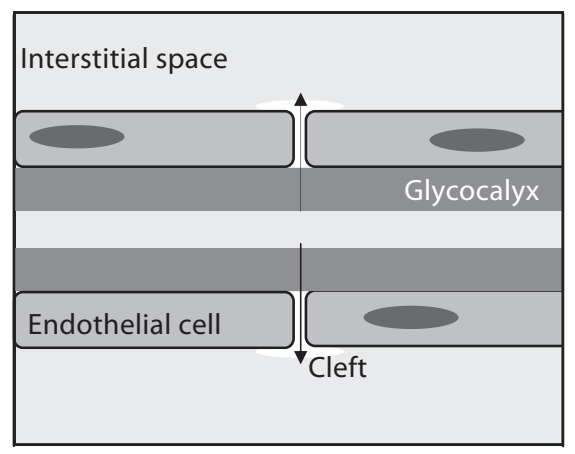

Fig. 4. The low-filtration concept of cardiac vascular/interstitial fluid handling. Schematic illustration (top panels), localization of infused albumin (middle panels, green color) and electron microscopical appearance of guinea pig hearts perfused with fixative for the glycocalyx (bottom panels, black stain), all as described previously $[7,13]$. Fixation of the glycocalyx entailed coronary perfusion over $1 \mathrm{~min}$ with $4 \mathrm{ml}$ buffer solution containing $2 \%$ lanthanum nitrate, $2 \%$ glutaraldehyde, $2 \%$ sucrose and 0.1 moles/l of sodium cacodylate ( $\mathrm{pH}$ 7.4). Heart tissue was then diced and left in this fixative for $2 \mathrm{~h}$ before being transferred into solution without glutaraldehyde for overnight fixation. The arrows indicate capillaries, the asterisk shows a venule.
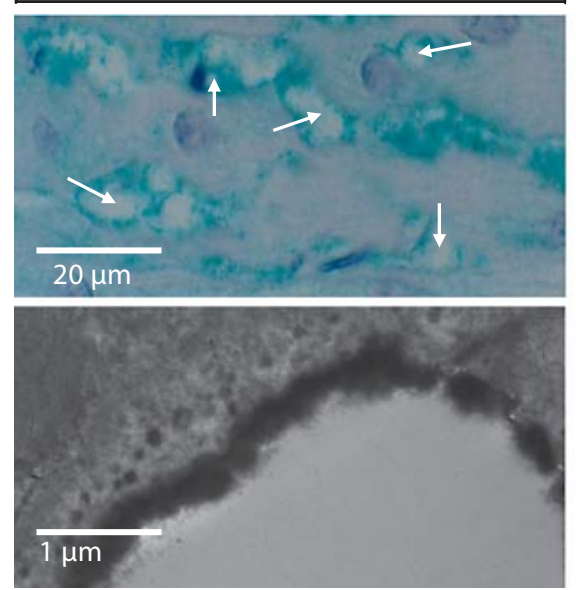

a
Venular segments
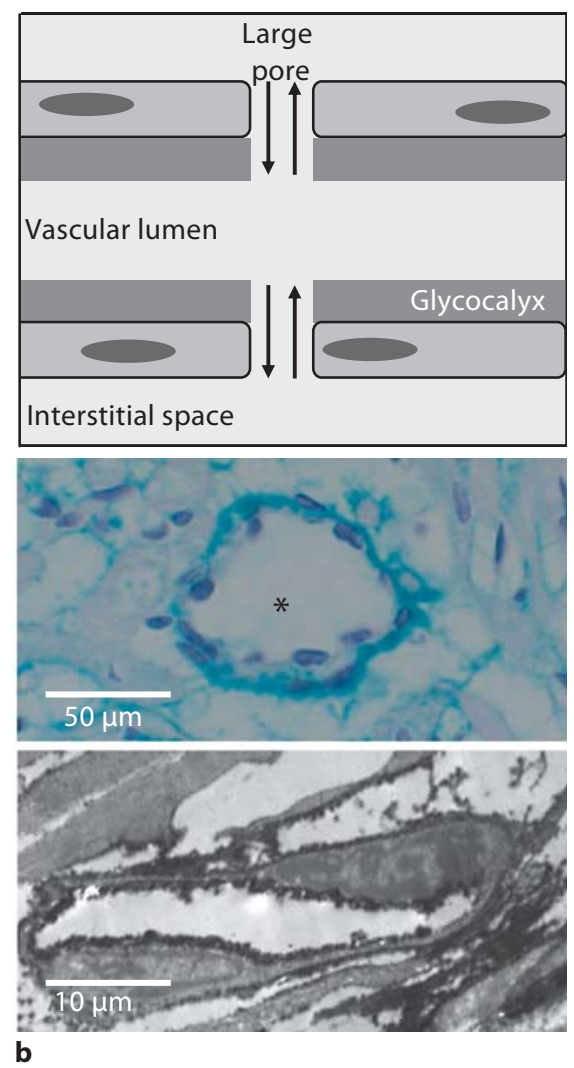

haps localized to arteriolar and capillary sites. Here it would provide the useful 'hemostatic envelope' proposed for whole vital organs [14] to ensure rapid sealing of lesions. Large-pore venular sections, conversely, should be devoid of tissue factor, allowing for intravascular/interstitial exchange of fluid, solute and colloid, as well as formation of lymphatic fluid with the potential to coagulate. Exactly such an intraorgan heterogeneity of distribution was observed in the present study.

High concentrations of tissue factor around arterioles and capillaries, representing those vessels where the endothelial glycocalyx normally prevents plasma proteins from leaving the vasculature [4], serve to initiate the extrinsic pathway of blood coagulation, should factor VII appear. This is synonymous with trauma and, consequently, immediate hemostasis via the TF/FVIIa complex is necessary. In contrast, the walls and interstitial space around the venules appear largely free of tissue factor, an indispensable prerequisite for maintaining physiological conditions according to the new concept of coronary fluid and protein handling [7]. Owing to the absence of tissue factor, no overwhelming coagulation should occur in these regions of plasma exchange with the tissue space.
The granular staining and location of tissue factor around small arteries, arterioles and capillaries is reminiscent of the morphology and localization of pericytes [15]. Some tissue factor was clearly located in cells away from the vascular walls, presumably cardiomyocytes. This has been reported already by Szotowsky et al. [10] for the human heart, but no details on distribution of tissue factor with respect to vessel provenience were given [10, 14]. Tissue-specific distribution of tissue factor, taken to indicate additional hemostatic protection of vital organs $[14,16]$, is now extended to a considerable heterogeneity of expression already within one and the same organ.

A powerful feedback inhibitor of prothrombin conversion to thrombin is the endothelial membrane protein thrombomodulin [17], which acts by promoting the generation of APC $[11,12]$. In our hands, thrombomodulin proved to be a splendid marker for vessels of all types in the coronary system. It was always localized to the luminal surface, but particularly high staining intensity was found at the junctions of endothelial cells in the venular and small venous vessel segments. This strategic localization would guarantee generation and passage of activated protein $\mathrm{C}$ into the interstitial space should any thrombin 
Fig. 5. Schematic outline of the distribution of pro-coagulatory (tissue factor, TF) and anti-coagulatory activity (thrombomodulin and activated protein $\mathrm{C}$ ) in human heart tissue in relation to vascular provenience. $\mathrm{EC}=$ Endothelial cell; $\mathrm{ESL}=$ endothelial surface layer; IS = interstitial space; $\pi_{c}=$ oncotic pressure in the vascular lumen of a capillary; $\pi_{\mathrm{e}}=$ oncotic pressure within the endothelial glycocalyx; $\pi_{\mathrm{g}}=$ oncotic pressure beneath the glycocalyx; $\pi_{\mathrm{T}}=$ oncotic pressure in the tissue; $\mathrm{P}_{\mathrm{T}}=$ hydrostatic pressure in the tissue; $\pi_{\mathrm{v}}=$ oncotic pressure in the vascular lumen of a venule; $\mathrm{P}_{\mathrm{v}}=$ hydrostatic pressure in the vascular lumen of a venule.
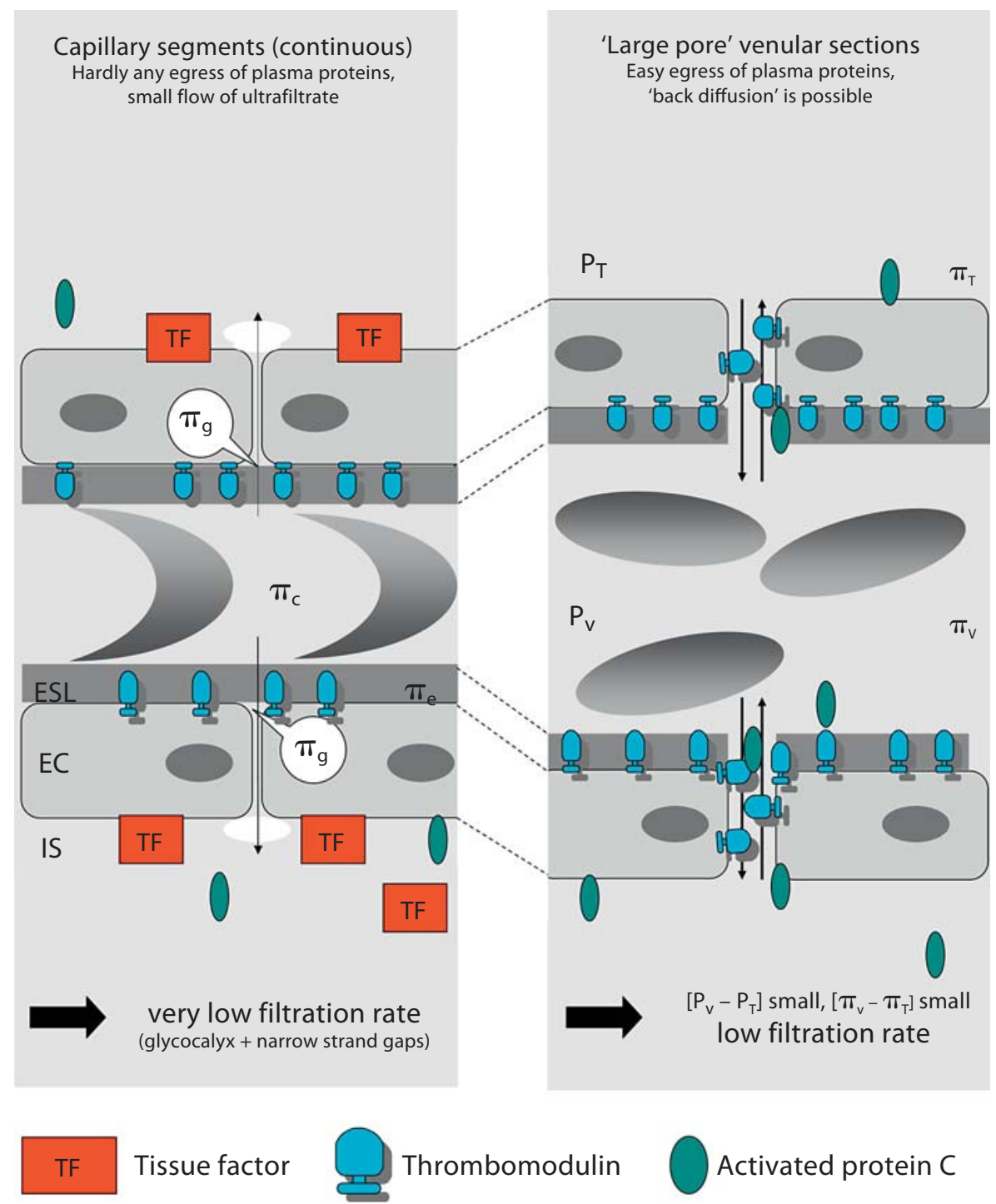

activity be present in the luminal plasma zone. APC is not only an anticoagulant but, via binding to cell membrane protein $\mathrm{C}$ receptors, may also initiate anti-inflammatory and anti-apoptotic effects. Important with respect to detecting localization in tissue is that receptor-bound APC will have higher permanence during staining and washing procedures. The antibody used by us in the present work was directed against the heavy chain of protein $\mathrm{C}$ and, therefore, recognizes both zymogen protein $\mathrm{C}$ and APC [18]. Heart tissue only stained for protein $\mathrm{C}$ at discrete extraluminal sites, noteworthy being the fact that these were sites that had proved typical for the localization of tissue factor (cf. fig. $1 \mathrm{~d}-\mathrm{f}, \mathrm{j}-\mathrm{l}$ ). It is, therefore, tempting to assume that APC is gathered there where the greatest risk exists for thrombin to be accidentally gener- ated in the interstitial space. This 'colocalization' of APC to tissue factor would thwart any untoward cleavage of fibrinogen under normal physiological conditions.

A shortcoming in our work is that, to date, we have investigated only few human hearts: 2 healthy hearts and 3 suffering from dilated cardiomyopathy. However, it is extremely difficult to get permission for human heart tissue to be immediately immersion-fixed after death. Although the dilated hearts obtained from the adults presented with marked tissue fibrosis, there were no apparent differences between the healthy and diseased hearts (including the heart pieces sampled from the 1-year-old subject with DCM) concerning the respective distributions of the coagulatively active factors investigated here. The presence of tissue factor in DCM heart tissue has been reported be- 
fore [10] and the similarity of distribution in all 5 hearts, despite the very diverse clinical histories, suggests a general principle. Indeed, functional heart disease should not lead to a change in the principle physiology of microvascular fluid exchange in the coronary system.

The pattern of distribution in relation to the three categories of microvascular coronary vessels (small arteries/ arterioles, capillaries and venules/small veins) resulting from our immunohistological findings is schematically outlined in figure 5. The distributions of tissue factor (around arterial and early capillary sections), thrombomodulin (on all vessel surfaces and particularly dense at venular endothelial cell junctions) and protein C (adventitial side of arterioles, capillaries and early venules) support the new perspective on microvascular fluid handling, at least in the myocardial tissue [7]. This new evidence further questions the classic view of Starling and supports a crucial, but probably not uniform, role of the endothelial glycocalyx for barrier function throughout the vascular bed of a whole organ. Moreover, in view of the heterogeneous distribution of pro- and anticoagulant factors, one may expect flow of interstitial fluid containing clotting factors to be regulated, with predetermined, preferential paths proceeding 'safely' to the terminal lymphatic origins. Indeed, such non-random, organized pathways of interstitial fluid movement should comply with another property of myocardial vessel anatomy, namely the reported parallel arrangement of arterioles and venules [19]. It certainly would not do for prothrombin and fibrinogen passing from venules to impinge directly onto tissue factor around arterioles (fig. 5). However, with APC present in the protein mixture introduced into the interstitium, as suggested in figure 5, the spatial proximity of arterioles and venules (separated by more than $500 \mu \mathrm{m}$ anyway [19]) may not be such a problem under normal conditions of fluid homeostasis and plasma hemostasis.

\section{Acknowledgements}

The authors are very thankful to Ms. B. Aschauer, Ms. U. Fazekas, Ms. C. Köhler, Ms. A. Sulz and Ms. S. Tost of the Institute of Anatomy, LMU Munich, for the conscientious and careful histological preparation of the samples of heart tissue. This work was performed using departmental research funding provided by the Bavarian State Ministry of Science, Research, and the Arts, $\mathrm{Mu}-$ nich. There are no further conflicts of interest to declare.

\section{References}

1 Langdell RD, Bowersox LW, Weaver RA, Gibson WS: Coagulation properties of canine thoracic-duct lymph. Am J Physiol 1960;199:626-628

2 Rusznyak I, Foeldi M, Szabo G: Lymphologie: Physiologie und Pathologie der Lymphgefässe und des Lymphkreislaufes, ed 2. Stuttgart, Gustav Fischer, 1969.

- 3 Starling EH: On the Absorption of Fluids from the Connective Tissue Spaces. J Physiol 1896;19:312-326.

-4 Adamson RH, Lenz JF, Zhang X, Adamson GN, Weinbaum S, Curry FE: Oncotic pressures opposing filtration across non-fenestrated rat microvessels. J Physiol 2004;557: 889-907.

5 Weinbaum S, Tarbell JM, Damiano ER: The structure and function of the endothelial glycocalyx layer. Annu Rev Biomed Eng 2007;9:121-167.

-6 Levick JR: Capillary filtration-absorption balance reconsidered in light of dynamic extravascular factors. Exp Physiol 1991;76: 825-857.

7 Jacob M, Bruegger D, Rehm M, Stoeckelhuber M, Welsch U, Conzen P, Becker BF: The endothelial glycocalyx affords compatibility of Starling's principle and high cardiac interstitial albumin levels. Cardiovasc Res 2007; 73:575-586.
8 Gebhard C, Stampfli SF, Gebhard CE, Akhmedov A, Breitenstein A, Camici GG, Holy EW, Luscher TF, Tanner FC: Guggulsterone, an anti-inflammatory phytosterol, inhibits tissue factor and arterial thrombosis. Basic Res Cardiol 2009;104:285-294.

-9 Mackman N: Role of tissue factor in hemostasis and thrombosis. Blood Cells Mol Dis 2006;36:104-107.

10 Szotowski B, Goldin-Lang P, Antoniak S, Bogdanov VY, Pathirana D, Pauschinger M, Dorner A, Kuehl U, Coupland S, Nemerson Y, Hummel M, Poller W, Hetzer R, Schultheiss HP, Rauch U: Alterations in myocardial tissue factor expression and cellular localization in dilated cardiomyopathy. J Am Coll Cardiol 2005;45:1081-1089.

11 Dorffler-Melly J, de Kruif M, Schwarte LA, Franco RF, Florquin S, Spek CA, Ince C, Reitsma PH, ten Cate H: Functional thrombomodulin deficiency causes enhanced thrombus growth in a murine model of carotid artery thrombosis. Basic Res Cardiol 2003; 98:347-352.

12 Esmon CT: Protein C pathway in sepsis. Ann Med 2002;34:598-605.
13 Chappell D, Jacob M, Hofmann-Kiefer K, Rehm M, Welsch U, Conzen P, Becker BF: Antithrombin reduces shedding of the endothelial glycocalyx following ischaemia/reperfusion. Cardiovasc Res 2009;83:388-396.

14 Drake TA, Morrissey JH, Edgington TS: Selective cellular expression of tissue factor in human tissues. Implications for disorders of hemostasis and thrombosis. Am J Pathol 1989;134:1087-1097.

15 Morikawa S, Baluk P, Kaidoh T, Haskell A, Jain RK, McDonald DM: Abnormalities in pericytes on blood vessels and endothelial sprouts in tumors. Am J Pathol 2002;160: 985-1000.

16 Maly MA, Tomasov P, Hajek P, Blasko P, Hrachovinova I, Salaj P, Veselka J: The role of tissue factor in thrombosis and haemostasis. Physiol Res 2007;56:685-695.

17 Becker BF, Heindl B, Kupatt C, Zahler S: Endothelial function and hemostasis. Z Kardiol 2000;89:160-167.

18 Fernandez JA, Lentz SR, Dwyre DM, Griffin JH: A novel ELISA for mouse activated protein C in plasma. J Immunol Methods 2006; 314:174-181.

19 Kassab GS, Fung YC: Topology and dimensions of pig coronary capillary network. Am J Physiol 1994;267:H319-H325. 